\title{
Celso Furtado e a "nação interrompida": a questão nacional e sua construção interrompida dos livros à SUDENE
}

\author{
Celso Furtado and the "interrupted nation": the national question and its interrupted \\ construction from books to SUDENE
}

\section{João Matias de Oliveira Neto}

Doutor em Sociologia pela Universidade Federal de Pernambuco Professor vinculado ao Departamento de Educação na Universidade Estadual da Paraíba (UEPB/Campus III) Pesquisador Associado 1 do Instituto de Estudos da África (IEAF-UFPE) j.matias@msn.com

\section{Valdênio Freitas Meneses}

Doutor em Ciências Sociais (CPDA/UFRRJ). Professor da Uninassau - Campina Grande/PB valdeniofmeneses@gmail.com

\begin{abstract}
Resumo: A questão nacional no Brasil republicano é objeto de reflexão e crítica de intelectuais os mais diversos, ecoando os já muitos estudos a seu respeito em países periféricos e não-periféricos. Este artigo tem por propósito analisar como Celso Furtado, ao destacar a necessidade de uma perspectiva histórica e socioeconômica da integração nacional, aliando a teoria à prática, promove um debate sobre a questão nacional que dialoga com significados outros da formação da nação no Brasil e no mundo, acrescentando o fato da nação estar "interrompida" por não superar as barreiras para uma integração nacional e social efetiva. Tal perspectiva é analisada no campo da prática quando observamos a atuação do intelectual paraibano à frente da SUDENE e do enfrentamento de projetos de poder de influentes lideranças políticas na Paraíba.
\end{abstract}

Palavras Chaves: nação; pensamento social brasileiro; Celso Furtado; Desenvolvimento; intelectuais.
Abstract: The national question in republican Brazil is the object of reflection and criticism by the most diverse intellectuals, echoing the already many studies about it in peripheral and non-peripheral countries. This article analyzes how Celso Furtado, by highlighting the need for a historical and socioeconomic perspective of national integration, combining theory with practice, promotes a debate on the national issue that dialogues with other meanings of the nation's formation in Brazil and in world, adding the fact that the nation is "interrupted" for not overcoming the barriers to effective national and social integration. This perspective is analyzed in the practice when we observe the performance of this intellectual at the head of SUDENE and the confrontation of projects of influential political leaders in Paraíba.

Keywords: nation; Brazilian social thought; Celso Furtado; Development; intellectuals. 


\section{Introdução}

Certamente a perspectiva de Celso Furtado sobre a formação nacional dialoga com uma tradição própria. É dele a chave para a compreensão da formação da nação pondo em questão, e de maneira bastante própria, a integração nacional do ponto de vista do desenvolvimento regional como um desafio, pesando que a noção de desenvolvimento supera a esfera puramente econômica para assumir um viés integrativo (mesmo criativo), ou seja, também regional, educacional, cultural e social. É sobre esta noção de formação nacional que ousamos pensar este trabalho; assim, sugerimos que Celso Furtado se refere a uma "nação interrompida" por ela não se afirmar perante a superação de um certo "fator de atraso" porque está submissa a projetos de nação outros que não aqueles que levariam o Brasil a superar suas disparidades econômicas, regionais e sociais; estes fatores, porventura, estão presentes na segunda parte deste trabalho, quando analisamos a disputa de Celso Furtado com líderes políticos na Paraíba da metade do século XX. Esta nação interrompida que se constrói porque, no terreno cultural, não se afirma em seu potencial de criatividade, sendo, portanto, uma criatividade igualmente interrompida; e não se afirma dentro da seara política e econômica porque é regional e socialmente dividida, mas dividida entre projetos de poder e de país que o próprio Furtado, como teórico e homem de ação, buscou combater dos livros à SUDENE.

A definição de nação é oriunda do século XVIII, segundo Eric Hobsbawm (1990), e somente ao longo do século XX os estados do planeta vieram a ser reconhecidos como estados-nação. Hobsbawm toma de empréstimo o termo "comunidade", um termo utilizado tanto por Max Weber (1974), para referenciar as comunidades políticas soberanas, como por Benedict Anderson (2008), para referenciar as comunidades imaginadas percebidas nos vínculos imaginários entre seus cidadãos. Também Celso Furtado (2013), neste ponto, abre precedentes para imaginar uma comunidade nacional entrelaçada por desigualdades regional e historicamente situadas, sobretudo ao pensar o desenvolvimento díspar e a necessidade de engendrar vínculos imaginários em comum para cunhar no Brasil uma noção de nacional por integração e não por suplantação das estruturas históricas esquecidas.

Antes, vale constatar, essa definição de comunidade é cara para as ciências sociais: ela advém de uma definição clássica de Max Weber (1974), que concebe a 
nação como uma articulação de valores culturais comuns como uma espécie de elo unificador do nacional, tornando as comunidades não apenas sentimentais ou narrativas, mas essencialmente políticas, uma vez que são reconhecidas como soberanas dentro de um determinado território político, fornecendo segurança em suas fronteiras e, a partir deste critério, aproximando a natio, enquanto dimensão cultural, do Estado, este entendido como ente protetor das fronteiras territoriais, das instituições e do poder coercitivo sobre os indivíduos.

Como nos referimos ao século XX, a questão nacional é vista por Hobsbawm (1990) como uma constante de movimentos de libertação neste século, bastando observar o processo de descolonização na África, as revoluções e o internacionalismo de poderes externos sobre os estados-nações constituídos. Também buscava-se articular as categorias de "classe" e "nação" para compreender critérios como o de cidadania plena e também a comunhão de valores e traços linguísticos, étnicos e culturais em comum. A aproximação da natio (conjunto de valores) do Estado (proteção de instituições e território) é um constante debate, uma vez que volúveis a épocas, influências e conflitos internos e externos. Celso Furtado (2013), por seu turno, busca a compreensão destes aspectos à seu modo, por exemplo ao refletir sobre a integração política de regiões desarticuladas entre grupos regionais antagônicos ameaçando o que seria a unidade nacional; bem como, ao refletir o dual-estruturalismo sobre as estruturas históricas do Brasil antigo e do Brasil moderno, isto é, dos dois "Brasis" evoluindo diferentemente, em uma unidade nacional, portanto, que têm à frente de si o desafio do "irredutível" das identidades regionais e o da consciência nacional.

Portanto, como os estados são essencialmente territoriais, dependentes de uma estrutura de coação e proteção que advém de uma comunidade política, segundo Weber (1974), falar sobre o que torna essa nação inteligível significa falar de como surge a consciência nacional. A aquisição de uma consciência nacional, ou seja, uma consciência de como a nação se forma sobre valores e instituições coercitivas não é vista por Hobsbawm (1990) como separada dos princípios de consciência política e social, isto é, das características que levam os cidadãos a pensar numa cidadania plena. De acordo com Ernest Gellner (1996), corroborando nossa compreensão sobre Max Weber, os Estados Nacionais são estados que ligam a soberania à cultura, o que descreve, por exemplo, no processo de transição de uma sociedade agrária para uma sociedade industrial, a ampliação da percepção sobre as diferenças culturais, com a cultura demarcando fronteiras de unidades sociais (GELLNER, 1996: 112). 
O modo como racionaliza-se a formação da nação, ainda em termos weberianos, dá-se quando Ernest Renan (1990) ressalta a importância de um "passado de violências" como algo substancial para o temor dos indivíduos caso não submissos a uma ordem racional-legal de proteção e identidade de grupo. Esta definição joga o entendimento sobre as nações em um limbo no qual esta, enquanto comunidade de valores em comum, necessita da proteção do Estado para proteger estes valores e modos de vida específicos. Para Weber (1974: 157), um “destino político em comum” organiza a memória dos vínculos entre os cidadãos de uma determinada comunidade em termos culturais, e esse vínculo fornece aos cidadãos uma forma própria de racionalizar a violência que os protege e legitima o estado-nação. Competiria aos intelectuais, estes porta-vozes de uma "verdade nacional", tal como Celso Furtado, socializar valores culturais e políticos da nação, dando sentido à existência do estado-nação (FEET, 2011) ao possibilitar que os valores comuns possam ser acessíveis às massas. Isso explica, por exemplo, o porquê de a questão nacional ser objeto de debate dentro do pensamento social brasileiro, seja em questões que tangem a formação da raça e cultura (valores culturais, sociais, científicos), seja em termos de formação do Estado nacional (instituições, símbolos e poder de coerção). Especificamente em Celso Furtado (2013), demonstra o quanto a noção de "centro de decisão", do ponto de vista burocrático, é necessária para que o Brasil reflita sobre suas dualidades históricas e engendre um plano da parte dos intelectuais e homens de ação para a superação dos chamados "fatores de atraso".

Com esse preâmbulo, temos em mente que temas como a formação do Brasil e a questão racial, social, econômica e identitária vem à lume com frequência no pensamento social brasileiro. De acordo com Renato Ortiz (2013), há uma obsessão pelo nacional fazendo com que a formação da identidade seja uma questão recorrente na América Latina e no Brasil. Antônio Candido (2011b), por seu turno, avalia que em meados de 1930 a crença de que o Brasil seria o país do futuro tomou corpo; e, com o universo da literatura e da cultura refletindo os dramas nacionais, uma "consciência do subdesenvolvimento" se formou para avaliar por que o Brasil é mais avaliado em termos de "faltas" do que de "sobras" de um futuro que o aproximaria das metrópoles tomadas como referência do que se pensava até então como civilização moderna. Ora, este tema passou pela ótica de autores tão diversos quanto Silvio Romero, Euclides da Cunha e Lívio de Castro, na virada do século XIX até o decorrer do século XX. É a partir desta conclusão que Candido (2006) avalia como as ciências sociais e humanas no 
Brasil se arvoraram de pensar a construção da nação, algumas vezes a partir de critérios evolucionistas para compreender a definição de raça, cultura e comportamento dentro do Brasil.

Para entender a posição de Celso Furtado neste âmbito, compreendemos que este caminho teórico acompanha a própria afirmação das ciências sociais como área do conhecimento, de uma ciência mais intuitiva até uma elaboração sistemática e metódica sobre os problemas nacionais, pontuada em fatos essenciais para a compreensão da realidade brasileira, como raça, pobreza e desigualdade social. Assim, pode-se dizer que desde 1930, com uma visão sobre o Brasil diferente da visão hegemônica do século XIX, a consciência do subdesenvolvimento foi se desdobrando em pensar o atraso material e a fragilidade das instituições nacionais que travavam a crença do Brasil como um país do futuro (CANDIDO, 2011a: 170). Para Candido (2011a), essa “compensação" do atraso viria com uma supervalorização do regional, evidenciando a realidade de solos pobres, das técnicas arcaicas, da miséria da população e da desigualdade social e econômica em nossa criatividade literária. A compreensão da identidade nacional, à época, e não por outro motivo, ganhou tons de reação à condição de periferia do capitalismo, dentro de um contexto global e transnacional, com o Manifesto Regionalista e com o Modernismo, no campo das artes, cultura e ciência ${ }^{1}$.

Não é dessa época, entretanto, que a batuta salvacionista dos intelectuais brasileiros era o que conduzia a preocupação sobre arranjar soluções para o Brasil. Para Ricupero (2011), as interpretações mais "intuitivas" do Brasil vêm desde o Brasil império e somente passaria a ceder espaço para a reflexão científica e sistemática do conhecimento universitário ao longo do século XX, do qual teóricos como Florestan Fernandes e Celso Furtado são exemplos categóricos. Ora, desde o romantismo essa "batuta salvacionista" dos intelectuais conduzia uma compreensão do Brasil ainda como objeto de idealização eurocêntrica, atravessando questões que surgiam com a proclamação da república e, depois, com o Estado Novo (SEVCENKO, 1983; ORTIZ, 2012). Para entender o papel de Celso Furtado como homem do Estado, precisamos ainda compreender que a "oficialização" da cultura como interesse de Estado advém da demanda de entender as mudanças sociais trazidas com a proclamação da república por parte, também, do Estado. Como o Brasil vinha sendo analisado segundo seu principal

${ }^{1}$ Para Celso Furtado, esses movimentos culturais de compreensão da realidade histórica do Brasil adentram a noção de criatividade, em termos de acúmulo e fluxo, exemplificada no livro Criatividade $e$ dependência na civilização industrial, como também na entrevista concedida pelo autor ao programa Roda Viva em 09 de fevereiro de 1987, quando foi Ministro da Cultura. 
norte de referência, ou seja, a Europa, caberia aos intelectuais, tornados homens de Estado e da burocracia, como demonstra Miceli (2001) resgatar o Brasil do "atraso intelectual" de uma nação periférica (BOTELHO, 2002).

Com isso, o dilema que iremos abordar aqui, a partir de Celso Furtado, dialoga sobre como ele compreende a defasagem entre teoria e realidade no modo de interpretar o Brasil e seus problemas. Assim, analisaremos que Furtado oferta uma visão tanto original como caudatária de seu tempo; bebeu em ideias estrangeiras e engendrou algumas novas, como indicamos neste preâmbulo. Em seu esforço de compreensão do Brasil, gestou uma teoria indissociável da prática, e enfrentou de frente as noções já pretéritas de fator de atraso e de país do futuro com que o Brasil foi pensado. Reflexo destas ideias se encontram de modo subsumido às suas práticas, ao refletir sobre a relação tensa de Celso Furtado com famílias e lideranças políticas na Paraíba.

Os tópicos a seguir se estruturam no sentido de apresentar, primeiro, como Celso Furtado pensou a nação interrompida e, como demonstraremos, interrompida em sua trajetória de ser integrada, nacional e criativa na resolução de conflitos, problemas e impasses inter-regionais. A seguir, analisaremos o homem de ação, isto é, Furtado como gestor da SUDENE e combativo mediante o poder de elites regionais. Ao final, vemos que a noção de uma nação interrompida nasce da assunção de projetos de nação distintos, conflitantes, na teoria e na prática; um lamento para Celso Furtado e uma marca de sua trajetória.

\section{Celso Furtado e a nação interrompida}

Vimos que um dos paradigmas para interpretação nacional ao longo do século XX se refere a como compreender a adaptação da sociedade ao meio ambiente onde vivem. Ao passo que os dilemas dos intelectuais se colocaram em como compreender a defasagem entre teoria e realidade, a chave para a compreensão da dimensão do "caráter nacional" para muitos estaria em como se combinam duas noções particulares: o meio e a raça, o que abriu espaço para interpretações deterministas e raciológicas sobre a mestiçagem, o negro e sua adaptabilidade ambiental (RICUPERO, 2011; ORTIZ, 2012). Podemos ampliar esta discussão, e fazer com que esta se dê segundo o 
paradigma de adaptação do ser humano ao ambiente onde vive, como um derivativo do que anteriormente foi pensado como a raça e o meio.

Ao tratar de como o desenvolvimento econômico no mundo gerou desigualdades, Celso Furtado assume que o Brasil se forma a partir de um "processo de integração política de regiões desarticuladas mas dotadas de um lastro cultural comum" (FURTADO, 2013: 338). Este lastro cultural comum, compreendido como a dificuldade de superação das crescentes disparidades regionais constituem ao mesmo tempo uma proximidade, em termos de identidade brasileira, mas um distanciamento, em termos de projeto nacional de integração de regiões cujo desenvolvimento econômico atinge níveis díspares e incapazes de restituir à população seus meios de vida. Nesta leitura, compreende-se que Furtado, à seu modo, reflete sobre valores culturais em comum em consonância com a formação de um Estado protetor weberiano, e atenta para a imensa disparidade que há entre um e outro para constituir o que Weber (1974) chamaria de um destino político em comum ao traçar o planejamento como uma meta para adquirir a formação de um Estado minimamente coeso na defesa de todo o seu território e de sua identidade cultural.

Não à toa, neste texto clássico, Furtado faz menção à tendência de abandono dos estudos de base no âmbito do Nordeste, assumindo que os estudos do meio significam o desenvolvimento de técnicas agrícolas específicas adaptadas para a realidade local, com capacidade para engendrar no nordeste uma economia de alta produtividade (FURTADO, 2013). Em vez de criar soluções próprias, limitam-se a transplantar soluções; evitando nos aprofundar, neste momento, no plano de ação via industrialização para superação das desigualdades regionais e integração do nordeste à nova ordem do desenvolvimento econômico, é com um ponto cego que Furtado vê a utopia de um nordeste integrado ao destacar que a região, no contexto de um país como o Brasil, seria um mero "grupamento regional", ao passo que sua indústria jamais poderia competir com a do sul do país. Há uma inegável disposição na leitura furtadiana para compreender as potencialidades da região, e compreendendo-as legar ao Brasil o seu sentido de uma comunidade política imaginada e integrada, talvez este o maior fator de busca do autor, por exemplo, por superar a "total incompreensão dos aspectos regionais em toda nossa política de desenvolvimento industrial" (FURTADO, 2013: $357)$.

Vemos neste texto que a preocupação do autor está em compreender os aspectos aparentemente involuntários que fizeram o desejo de industrialização concentrar-se no 
Centro-Sul do país, devidamente alimentado pelo consumo das outras regiões. A disparidade de ritmos de crescimento entre as economias do Nordeste e do Centro-Sul seriam apenas uma consequência desse aparente "involuntariado". O que talvez Furtado não tenha atentado neste texto seria a possibilidade de haver projetos nacionais distintos, baseado muitas vezes na compreensão do nordeste como signo do atraso brasileiro, conforme se vê na construção dos intelectuais, homens de ciência e de política (VELLOSO, 2010). E este signo do atraso também se liga, sob nossa interpretação, a fatores raciais, uma vez que a crença no nordestino preguiçoso e caricato é uma constante, não só na literatura e na cultura, como também em compêndios educacionais do começo do século XX (BOTELHO, 2002).

Aqui ensaiamos uma sugestão de pensar este problema. Privilegiar o Centro-Sul em termos de industrialização foi uma maneira distinta da de Celso Furtado de pensar o meio e a raça enquanto projeto nacional de nítido branqueamento da população, inclusive tratando o desenvolvimento do Brasil como um projeto nacional de minorias brancas, concentrando-o no Centro-Sul também por uma questão de privilegiar áreas de maioria branca e ascendência europeia (SKIDMORE, 2012). Se à época a imagem do nordeste esteve associada ao mulato, à seca, à preguiça e demais características intrinsecamente raciais, o nordeste seria um estorvo ao desenvolvimento do Brasil industrializado e branqueado (SCHWARCZ, 1993; BOTELHO, 2002). Ainda que não tenhamos a intenção de reduzir o debate sobre o nordeste à questão racial, nem imputar a Celso Furtado um horizonte de perspectivas que não era o seu, talvez Celso Furtado não haja atentado para uma possível dimensão racial para o desenvolvimento, dimensão esta instilada por toda a literatura, cultura e pseudociência a estigmatizar os ditos raciológicos do século XIX ainda permanentes ao longo do século XX (SCHWARCZ, 1993), sobretudo em relação ao modo como o nordeste foi observado no território da cultura, costumes e crenças; e ao modo como o nordeste é observado em outras regiões do país, sobretudo (ALBUQUERQUE JR., 2009)

À parte o fato de Celso Furtado pontuar toda a sua obra desta fase desenvolvimentista a cultuar e divulgar o nordeste como uma região promissora, como se quisesse incutir nos investidores e demais homens de ação a ideia de um nordeste viável para uma efetiva integração nacional, social e, ousamos dizer, racial, do ponto de vista da conquista da cidadania plena, há uma perplexidade contínua, por parte do Celso Furtado, em não observar o "direito que tem o povo de sobreviver" (FURTADO, 2013b: 365). Ao mesmo tempo, o setor para o qual Furtado dirige sua bibliografia, muitas vezes 
em tom de apelo, seria o responsável por desenvolver a noção de criatividade junto à de desenvolvimento. Assim, em um texto de 1984, Furtado esboça que o desenvolvimento não é compreendido por ele apenas enquanto processo de acumulação e de aumento da produtividade macroeconômica, mas sobretudo "via de acesso a formas sociais mais aptas para estimular a criatividade humana e para responder às aspirações de uma coletividade" (FURTADO, 2013b: 368).

Criatividade esta, portanto, associada a um desejo genuíno de observar, no território do Nordeste, formas sociais que podem ser observadas na região Centro-Sul industrializada, em que o acesso a bens de consumo, maiores salários, melhores empregos e bens duráveis legaria a posse de instrumentos capazes de compreender a modernidade de forma criativa e minimamente inclusiva. E então o setor agrário passaria por uma ideia de renovação necessária, sobretudo no modo como o Brasil enxerga a monocultura, levando Furtado a afirmar que tais estruturas, assim como o próprio desenvolvimento, são frutos de uma opção política orientada, sobretudo no processo de decisão sobre tornar ou não agricultores artífices do desenvolvimento, desconcentrar ou não a distribuição de renda inter-regional, investir ou não em geração de novos empregos. Ou seja, em todos os níveis Furtado deixa claro que o que caracteriza o desenvolvimento é seu projeto social subjacente, tomando a industrialização adaptada às peculiaridades continentais e regionais do Brasil como um impulsionador. Para o crescimento econômico se metamorfosear em desenvolvimento, há que haver melhoria das condições de vida da população. E isto não se dá espontaneamente: é a realização de um projeto e de uma vontade política (FURTADO, 2013b); então diríamos, de um projeto nacional.

Ao tratar do federalismo, Furtado deixa claro que este está relacionado não só ao projeto político de unificação do país, mas de observar as aspirações de desenvolvimento nas distintas áreas do território brasileiro, destacando que não haveria entre nós "choques de nacionalidades, de agressões culturais ligadas a disparidades étnicas ou religiosas" (FURTADO, 2013c: 378). Discordamos do economista neste ponto, destacando que, mais uma vez, ele parece trazer consigo uma noção freyriana de harmonia social e cultural no terreno das desigualdades sociais (FURTADO, 2013e), que para Furtado parecem ser de ordem mais econômica e social do que nacional e cultural no sentido do aprofundamento no estudo do racismo estrutural e da configuração psicossocial do negro e do mulato na sociedade de classes, como deixaria claro na sociologia brasileira Florestan Fernandes (2005). Mais uma prova, portanto, de 
que a desigualdade regional, em termos de desenvolvimento, levaria Furtado a encampar uma luta macrossociológica para a compreensão das desigualdades, sendo esta a sua aposta na crítica à dependência econômica de algumas regiões com relação a outras, da dissonância nas relações entre elas, da transferência unilateral de recursos (FURTADO, 2013c).

Aprofundando este ponto, Furtado argumenta que na diversidade de regiões mora uma riqueza cultural, mas para que esta riqueza venha à lume é necessário um desenvolvimento material mais equânime entre as regiões. Para ele, a formação da nacionalidade brasileira se dá em um movimento pendular de distribuição do poder político, "que não seria fácil explicar sem a consciência que cedo amadureceu entre nós de que somos um povo com um compromisso com o futuro" (FURTADO, 2013c: 378379). Ao afirmar, por exemplo, tanto que há esse compromisso com o futuro, uma vez, como observamos, que no pensamento brasileiro se visualizou por décadas diversos "fatores de atraso", Furtado arremata que uma consciência da unidade nacional coexistiria com o senso de identidade que se desenvolveu de forma muito particular em cada região. E assim, assevera: "A identidade do brasileiro tem raízes em sua inserção regional, sendo de menor peso a dimensão religiosa ou étnica" (FURTADO, 2013c: 379).

A visão macrossociológica de que parte Furtado o leva a perceber a construção nacional brasileira a partir de um grande consenso a ser estabelecido entre regiões sobre o desenvolvimento, tomando o centralismo do Estado como um fator constituído. E nos parece, portanto, que este é o termo certo: o consenso. Através dele o Brasil chegaria a uma noção de identidade nacional pela via da integração regional, com as regiões compreendendo-se em suas diferenças e necessidades para o desenvolvimento. Tanto que, para Furtado, uma dita pulsação do centralismo-federalismo, para compreensão das distâncias regionais que fazem o Brasil, deve ser localizada na história levando em conta dois fatores de nossa cultura: a consciência de unidade nacional e o "irredutível" da identidade regional (FURTADO, 2013c). Uma síntese, um consenso, portanto, para o Brasil ser o "país do futuro", corrigindo os aspectos negativos das desigualdades regionais e revendo a interdependência inter-regional, a concentração geográfica de renda, o centralismo político-econômico e os impedimentos para uma nação “interrompida" ser uma nação de fato. A saber, refazendo essa noção da necessidade de um consenso, 
De toda forma, a industrialização apoiada no mercado interno deu origem a vínculos profundos entre regiões que antes mantinham entre si débeis relações econômicas. A unidade nacional já não se circunscrevia ao plano subjetivo, pois penetrava os interstícios da vida dos cidadãos. Se tem em conta esse dado, percebemos sem dificuldade que o centralismo político é, hoje em dia, uma redundância, porque contribui para agravar os notórios aspectos negativos do centralismo econômico. (FURTADO, 2013c: 382)

É na concentração de renda e riqueza que baseia a crítica de Celso Furtado à comunhão da unidade nacional com as identidades regionais, estas traduzidas não só em valores em comum, mas também dificuldades em comum dentro de seu próprio território, tendo, para tanto, a industrialização como fator de integração e desenvolvimento inter-regional. Afora ela, e talvez o lugar onde Furtado apresente mais a sua face de economista heterodoxo, a abordagem sobre criatividade e dependência na civilização industrial é o que relaciona processos de mudança social, visões sobre a história da sociedade, o desenvolvimento e seu potencial criativo. A criatividade reflete a aptidão de membros da sociedade para "formular hipóteses, solucionar problemas, tomar decisões em face da incerteza" (FURTADO, 2013d: 461).

Em sua teoria econômica, o autor relaciona a criatividade aos excedentes, consequência mesma de intercâmbios com outros grupos humanos ou simplesmente acesso a recursos naturais mais numerosos. Ou seja, Furtado aborda sob suas próprias palavras uma noção culturalista da economia dos povos, como se constata em seu texto sobre a cultura brasileira (FURTADO, 2013e); recorre, ainda que indiretamente, a Franz Boas e Gilberto Freyre para, à seu próprio modo, dizer que os intercâmbios, não apenas de produtos e mercadorias, mas de pessoas, influências e culturas é capaz de gerar excedentes, estes compreendidos, a nosso ver, como perspectivas de crescimento e reprodução, seja de experiências como de soluções possíveis, para nossos problemas estruturais. Aqui, portanto, adentra uma visão filosófica e culturalista da teoria econômica, uma vez que a criatividade se relaciona com a inventividade. A saber, "Em sua dupla dimensão de força geradora de novo excedente e impulso criador de novos valores culturais, esse processo liberador de energias humanas constitui a fonte última do que entendemos por desenvolvimento". (FURTADO, 2013d: 462)

Neste aspecto, Furtado encarna uma visão panglossiana da criatividade como propulsora irrevogável do desenvolvimento e deste para a felicidade e potencialidades "insondáveis" do homem, referindo-se a civilizações "não superadas" (pelo potencial de 
criatividade), ao teatro grego (tomando o aprofundamento da identidade cultural como penetração nas raízes míticas do subconsciente coletivo), a experiências intensas de percepção do mundo e de si. Em alguns aspectos, o autor se aproxima mesmo da sociologia da cultura, ao descrever o "campo do possível no que concerne à criatividade" como dado para entender as "leis da criatividade cultural" (FURTADO, 2013d: 462). Resta compreender, entretanto, que a noção furtadiana de criatividade é relacionada ao papel de tradução dos intelectuais dos significados simbólicos da nação para o povo, como se refere Max Weber (1974) em seu texto clássico. Tal criatividade, não por menos, é o que aprofunda, na visão furtadiana a perspectiva de uma unidade nacional das identidades regionais, de um ponto de vista a partir do qual se tornaria inviável a construção de uma unidade nacional sem o pressuposto do aprofundamento da criatividade regionalizada.

O esforço de compreender uma nação "interrompida", portanto, passa por compreender como a privação de recursos leva os indivíduos a não participarem do "arranjo da própria vida", reduzindo suas experiências e conhecimentos a formas simples de mimetismo social. Esta visão demonstra que não apenas a formação de uma nação, mas também do indivíduo depende desta criatividade. Assim, na ausência dela:

A possibilidade de criar algo para si próprio ou no quadro das relações pessoais míngua: a vida como projeto original tende a ser substituída por um processo de adaptação a estímulos exteriores. O indivíduo poderá reunir em torno de si uma miríade de objetos, mas sua participação na invenção destes terá sido nula. Os objetos que adquire e substituía a qualquer instante podem proporcionar-lhe "conforto", mas carecem de uma vinculação mais profunda com sua personalidade. (FURTADO, 2013d: 465)

Neste ponto, Furtado tanto emula o esforço de pensar uma sociologia dos objetos, para entender o universo da cultura, como recorre ao individualismo metodológico para compreensão da ação social e da dominação dos objetos sobre os indivíduos. Também emula uma forma de pensar as relações de consumo, traçando a relação entre a produção dos objetos, o processo de acumulação e a homogeneização dos padrões de consumo. Mas, principalmente, afirma que pensar a influência dos objetos sobre os seres humanos é uma maneira de viver com o que nos é externo. Para ele, a criatividade política é capaz de gerar formas políticas próprias, propiciando 
espaços políticos em que se manifestem os antagonismos de forma própria e consciente. Uma vez que a atividade política seria essencial para a criatividade no plano institucional (FURTADO, 2013d), a inovação das formas sociais depende disso, além da redução das tensões geradas pela acumulação; daí a inevitabilidade das transformações sociais ser algo esperado, sobretudo quando relacionadas a imensas disparidades regionais, disparidades de acesso à ciência e tecnologia, disparidades de acesso à educação e cultura.

Por esta perspectiva, quanto mais as disparidades regionais aumentam, acentuam-se seus diferentes desenvolvimentos institucionais e políticos, separando as regiões de uma perspectiva de nação unificada. A industrialização propicia diferentes modelos de apropriação da criatividade, que é geradora de diferentes maneiras de pertencer ao mundo. Ao passo que a acumulação capitalista cria suas antinomias sociais mais agudas, cria-se também a oportunidade de desenvolvimento das qualidades intelectuais em uma região e não em outra. E quando o debate se estabelece entre classes, uma massa da população segue mantida sob tutela; ou seja, sua participação no processo político fica sob o controle de grupos dirigentes que integram as estruturas de poder. Esse processo, para Furtado, leva à subserviência da acumulação dependente e ao mimetismo político, reproduzindo fórmulas prontas de confrontação das mudanças sociais, levando a criatividade nacional a um imobilismo refém de lideranças populistas. Este movimento, por sua vez, atesta a falência da criatividade.

Pensar a nação interrompida em Celso Furtado é, sendo irônico com sua própria definição, refletir sobre o "campo do restrito". A bibliografia furtadiana trata, ora em tom de lamento, ora de apelo, para a superação dos "fatores de atraso" pelo ponto de vista da criatividade (polissêmica), da integração nacional e do desejo macroestrutural de integração de classes no modelo capitalista de industrialização. Trata também das restrições, que são de natureza estrutural, histórica, econômica e cultural. A nação, desta maneira, é "interrompida" porque restrita em seu potencial criativo, não apenas de criatividade política e institucional, mas de criatividade cultural com a situação a que está relegada uma massa de trabalhadores, divididos por identidades regionais e empecilhos estruturais e regionalizados ao desenvolvimento da criatividade.

Trabalhando pelo consenso, o economista paraibano confia que o motor do desenvolvimento não é só econômico, mas político, cultural e humano. Para que se realize, precisa do esforço necessário para sair das crises e dos problemas de forma criativa; não dependente, nem mimética. Uma saída que se esboce no desejo de 
desenvolvimento atravancado por heranças históricas atávicas, pouco assumidas por Furtado em termos revolucionários (como assumida por outros pensadores do seu tempo), mas denunciadas e até lamentadas no esforço de compreensão do porquê o Brasil não abandona seu caráter retardatário e adentra uma modernidade da própria criatividade e do desenvolvimento humano num nível inter-regional e integrado.

\section{A SUDENE e o projeto de (n)ação}

Entre 1930 e 1950 o Brasil passou por uma profunda transformação social. De uma recém fundada república estruturada ao redor de "ilhas" de plantações agroindustriais de café, cana de açúcar, cacau, algodão e borracha, o país se firmou como um "continente" marcado pela rápida industrialização e urbanização (GARCIA JR, 2007: 73). Essa mudança não se deu sem tensões políticas. O que economistas como Bresser Pereira (2015) chamaram de "Pacto Nacional-Popular", iniciado em 1930 e que durou até 1960, foi marcado por um período turbulento. Na primeira década, esse pacto foi dirigido por um governo revolucionário exercendo autoridade por medidas provisórias e passando por conflitos armados, transitou de uma constituinte em 1934 para um "autogolpe" de Estado em 1937. No plano da geopolítica, há uma inserção do Brasil ao lado dos vencedores na $2^{\mathrm{a}}$ Guerra Mundial durante o período do "exilio" e o retorno de Getúlio Vargas - antes ditador, até 1945, e eleito presidente em 1950. Por fim, a disputa que envolvia a consolidação de uma estrutura de Estado - do serviço público a leis de trabalhistas modernas - e de controle dos recursos naturais se acirra: por ai moveram alguma das peças políticas que culminariam no suicídio de Getúlio Vargas (1954) e na eleição de Juscelino Kubitschek (1956) e que teve sua legitimidade de ser defendida por uma espécie de "contra-golpe" encabeçado pelo Marechal Henrique Teixeira Lott. Deixando pra trás os fantasmas do Palácio do Catete, no Rio de Janeiro, o projeto político desenvolvimentista de JK fixava em pleno cerrado a modernidade arquitetônica da nova capital chamada Brasília.

Essas tensões econômicas e políticas deixaram "fios desencapados" na construção de um sentido de nação. O governo JK e seu movimento centralizador tinham de lidar com as disparidades regionais. O caso da região Nordeste se tornara singular e dramático: a antiga região chamada de "Norte" do Brasil perdera sua 
influência econômica desde o século XIX, tendo setores canavieiros e pecuaristas ocupado espaços cada vez mais secundários na política nacional. Em termos de participação do PIB, o Nordeste chegara ao final da $2^{\mathrm{a}}$ Guerra Mundial com $11 \%$ apenas do todo nacional (FURTADO, 1983: 19). Por outro lado, à revelia da derrota econômica e política, foi no Nordeste que se criou um imaginário poderoso de nação fortemente associado às secas, às revoltas populares e messiânicas, da literatura regionalista e do saudosismo das casas-grandes e fazendas pecuaristas. Conceito geográfico inexistente até inicio do século $\mathrm{XX}$, a ideia de divisão territorial e principalmente simbólica que evoca um "Nordeste do Brasil" já seria algo naturalizado por volta de 1950. (VESENTINI, 2014) $^{2}$.

Com o doutorado em na Sorbonne na França (1948) Furtado retorna ao Brasil junto ao DASP. Em 1949, vai ao Chile e atua junto a CEPAL na companhia de nomes como Raul Prébisch. No inicio da década de 1950 Furtado volta ao Brasil e lidera uma comissão mista BNDE/CEPAL, vinculo de órgão financiador do governo Getulio Vargas. Após 1953, Furtado tem um "interstício" de cerca de 5 anos em Cambridge, convidado pela rede acadêmica local, momento em que escreve o esboço do livro Formação Econômica do Brasil - lançado em 1959.

Nesse período Furtado uniu primeiro um exercício profissional de operador de políticas econômicas - que à época tinham como "espelho" a experiência dos países reconstruídos do pós $2^{\text {a }}$ Guerra Mundial - e ocupação de cargos de visibilidade pública. Depois a formação acadêmica como profundo conhecimento das dinâmicas históricas, econômicas e políticas que levam ao subdesenvolvimento - a nível amplo mundial até na dinâmica interna de regiões de um país. Ciente desse potencial de Celso Furtado e também do problema da desigualdade regional como ameaça ao projeto nacional desenvolvimentista, o presidente JK convidara o paraibano a assumir a Superintendência de Desenvolvimento do Nordeste (SUDENE). Sendo ligada ao poder executivo, a Sudene traria um grau de recursos para planejamento de ações, o que dava importância próxima a um ministro de estado para o cargo de superintendente. Aceito convite feito por JK, Furtado tinha à frente uma missão pública de lidar com uma região que já apresentava níveis de miséria e uma turbulência de conflitos agrários. A atuação

\footnotetext{
${ }^{2}$ Impressiona que autores de abordagens díspares tenham estudado um processo similar do Nordeste no imaginário nacional. Como aponta Vesentini (2014) o conceito geográfico de Nordeste se divide entre várias correntes: da geografia de Manuel Correa de Andrade, aos estudos de economia política de Francisco de Oliveira até à historiografia de Durval Muniz Albuquerque Jr. Essas três correntes fizeram com que o Nordeste, "longe de esquecido" fosse a região mais estudada do Brasil em termos de ciências humanas.
} 
de movimentos de organização de trabalhadores, como as Ligas Camponesas - exigindo reforma agrária e direitos trabalhistas modernos e até "obrigações morais", como caixões para enterro de seus mortos - alimentou um temor geopolítico nos $\mathrm{EUA}^{3}$ de que caso acontecesse uma "Revolução Cubana" no Brasil, ela se daria a partir do Nordeste brasileiro.

Os estudos publicados sob o título de Grupo de Trabalho para Desenvolvimento do Nordeste (GTDN) são tidos como documentos fundadores da Sudene. Esses estudos trazem uma leitura desenvolvimentista diante do grave problema da disparidade regional entre a economia do Centro-Sul e o Nordeste do Brasil. O GTDN colocava a teses cepalinas para pensar soluções para um problema de divisas de economia, de mão de obra e fluxo populacional da região Nordeste que tinha uma pressão fundiária sobre a produção de alimentos. Este fator, quando agravado pelas secas, era uma das grandes causas de um impacto populacional e na mão de obra: seja pelo drama humanitário dos retirantes sob risco de morte por fome e doenças seja pelas frentes de trabalho e de migração para o Centro Sul. Nessa proposta de uma resolução pacífica e reformista para os problemas sociais graves havia uma demanda de criar uma economia adaptada a conviver com as secas inevitáveis. No caso da economia rural, isso passava pela modernização de fazendas, de técnicas de forragens arbóreas que se adaptem às condições mesológicas (...) que poderiam constituir o núcleo de uma economia de elevado grau de razoável nível de produtividade e adaptação (FURTADO, [1959] (2009): 145-147). O pacote da Sudene tinha medidas de industrialização de médios a grandes centros urbanos além de uma ousada proposta de mudanças demográficas para o semiárido rural como abertura de uma frente agrícola para deslocar um fluxo populacional do semiárido para lotes na região do Maranhão (FURTADO [1959] (2009): 150).

A Sudene fez inserção em um campo acirrado de cargos, recursos e projetos de ação já ocupado por outros entes estatais. Já se passara cerca de quarenta anos de existência da Inspetoria de Obra Contra as Secas (IOCS), criada em 1909, fruto de ações de combate às secas já propostas desde escolas de engenharia do império (CAMPOS, 2014). Após a década de 1930, o IOCS se tornaria departamento (DNOCS), com os orçamentos voltados para obras contra as secas ganhando mais espaço do que o

\footnotetext{
3 A. Para notar a temperatura política desse momento, assistir documentário " Brazil The Troubled Land" (https://www.youtube.com/watch?v=jWq4 898mg) . Para entender esse cenário em relatos " in loco" e fontes primárias pode-se indicar as leituras de Julião [ 1962] 2009 e Callado (1960). Para uma análise sociológica dos processos políticos e uma sociogênese das Ligas Camponesas ver Gennaro (2019).
} 
de ações emergenciais em ministérios como o da Viação e Obras Públicas (DANDARO; MARCONDES, 2018).) Essa infraestrutura estatal ganharia capilaridade junto a companhias atuantes no São Francisco como Comissão do Vale do São Francisco (CVSF) e Companhia Hidrelétrica do São Francisco (CHESF) até financiadores como Banco do Nordeste $(\mathrm{BNB})^{4}$ consolidados tanto no Estado Novo (1935-1945) e durante o período democrático do governo de Getúlio Vargas (19501954).

Diante desse mapa já ocupado de quadros e instituições, a dificuldade da Sudene em "acomodar" cargos e espaços de poder estabelecido seria ilustrada logo nas primeiras reuniões do comitê. A experiência dos conselhos deliberativos da Sudene obrigaria Furtado a sair das silenciosas horas de estudos e ponderados debates acadêmicos sobre as teorias de Keynes, Marx, Mannheim e outros nomes da economia e ciências sociais para encarar ruidosos Sampaios, Figueiredos, Cavalcantis, Gondins, Alves, sobrenomes "de tradição" e poder local aos quais pertenciam os homens da política no Nordeste. Estes jogavam suas investidas, ora para esvaziar a possibilidade de execução do projeto da Sudene, principalmente no tocante à reforma agrária, ora para "colonizar" a Superintendência aos seus interesses, assim como já tinham feito com DNOCS e o BNB. Rosa Freira D'Aguiar (2009: 8), através de pesquisa em recortes de jornais, menciona uma chuva de "bilhetinhos" de deputados após uma reunião da Operação Nordeste em fevereiro de 1959, junto ao presidente Kubitschek, em que estavam presentes Furtado, Dom Helder Câmara, ministros e governadores:

A verdade é que ninguém sabe até onde se prolongariam as discussões, caso o presidente não se houvesse antecipado aos governadores. A própria amostra da reunião do Catete, onde após Cid Sampaio [ governador de Pernambuco] falar em nome de todos os governadores, por delegação, o chorrilho de bilhetinhos de deputados começou a pressionar a eloquência de seus governantes, provocando um rosário de reivindicações locais, justificou de certo modo o tom paternalista da reunião. (D’AGUIAR, 2009: 8)

É nesse ponto que se insere um parlamentar que Furtado afirmou em entrevista ${ }^{5}$

\footnotetext{
${ }^{4}$ O Banco do Nordeste do Brasil foi criado em 1952, com a finalidade de financiamento público/privado de obras de infraestrutura e auxílio nas obras de emergências. A ideia foi formulada pelo então ministro da fazenda Horácio Lafer, em 1951 a partir de uma estrutura de financiamento, além de um grupo de estudos (ETENE) para diagnosticar potencialidades e fragilidades econômicas regionais.

5 Entrevista de Celso Furtado concedida em 1997 a Adriano Sarqui Bezerra de Meneses, gerente da
} 
ter sido o "seu maior inimigo" nas brigas da Sudene: o parlamentar Argemiro de Figueiredo. Nascido em Campina Grande ${ }^{6}-\mathrm{PB}$, oriundo de famílias de pecuaristas e algodoeiras locais, Figueiredo foi governador entre 1935-1940 e em seguida partiu para sucessivas eleições de deputado a senador. Tido como um conciliador do período posterior a uma violenta crise politica na Paraíba após $1930^{7}$, Figueiredo ascendeu ao parlamento como forte ligação dos setores rurais do Estado. Enquanto senador, usou a tribuna várias vezes para discursos virulentos de resistência e crítica a Sudene e ataques pessoais à figura de Celso Furtado. Esses discursos foram feitos tanto no governo JK como no governo Jânio Quadros e João Goulart no período de 1959-1963. Nos primeiros desses discursos registrados em anais do senado, Figueiredo reforçava um incômodo com as propostas de industrialização, o deslocamento de parte da população para lotes e uma frente agrícola fora do semiárido. Por fim, reforça a demanda contrária a uma pauta que o GTDN era crítico: a solução hidráulica.

Alguns dos vários ataques na tribuna feitos por Argemiro de Figueiredo entre 1961 e 1962 podem ser encontrados na Revista Informação Legislativa de 1983: nesse período, dos 20 discursos registrados nos anais do Senado, 13 continham críticas diretas e menções negativas à Sudene ou a Celso Furtado (MENESES, 2016: 97). A saber,

Já disse, e repito. É um erro catastrófico para a região nordestina essa prioridade que se pretende assegurar o problema da industrialização, como processo técnico de recuperação econômica e de combate ao flagelo das secas. [...] Em pouco ou nada irá influir, na vasta zona do polígono, a formação de núcleos industriais, por mais poderosos que sejam, uma vez que

Etene, e João Salmito Filho, estudante de Ciências Sociais da Universidade Estadual do Ceará. Essa entrevista foi publicada com o título de GTDN e as exigências da atualidade no último capítulo (p. 267283) da coletânea Nordeste e a saga da Sudene (1958-1964).

6 Nessas mesma cidade houve uma conferência dos bispos (1957), evento tido como um dos principais agregadores de forças políticas que pressionaram a criação da Sudene.

7 Em 1930, o governador João Pessoa foi assassinado na confeitaria Glória, em Recife, pelo jornalista João Dantas. O motivo do crime foi uma mistura de oposição política e "honra", devido à publicação, nos jornais ligados aos partidários de Pessoa, de fotos e cartas intimas de Dantas com a professora e poetisa Anayde Beyriz. A comoção pela morte do governador fez com que a capital do estado mudasse de nome — de Parahyba do Norte para João Pessoa - e deu início também a uma onda de violência e perseguição contra os oposicionistas de Pessoa - os "perrepistas" - em toda a Paraíba. Em Campina Grande, Argemiro de Figueiredo, mesmo do lado liberal, teve de dar proteção a alguns parentes do lado "perré", como o primo José Agra, que foi atacado por uma multidão furiosa e teve sua casa saqueada e incendiada (SYLVESTRE, 1993: 102-103). Com a reorganização do tabuleiro político da Paraíba e do Brasil após 1930, e no exílio do irmão e com o afastamento do pai da vida pública, Argemiro assumiu, em 1932, a liderança política da família Figueiredo. Partindo do cargo de secretário do interior nos governos de Álvaro de Carvalho e José Américo de Almeida. Figueiredo seria eleito governador em 1935 e permaneceria no cargo até 1940. 
permanecerá exposta a calamidade de toda a imensa população rural abrangida pelo fenômeno climático [...] (REVISTA INFORMAÇÃO LEGISLATIVA, 1983: 25-26)

Argemiro de Figueiredo também articulou para votação no Senado um projeto que rivalizaria politicamente com a Sudene: uma ementa para dar autonomia ao DNOCS em relação ao controle da Superintendência (COSTA LIMA, 2009: 229). Tensões entre Sudene e DNOCS podiam ser vistas nas reclamações de Furtado sobre a demora da diretoria do departamento para enviar relatórios e dados pluviométricos à Sudene. Da parte dos setores representados por Figueiredo, havia esperança de que nessa "demora" fosse dado tempo de uma nova eleição presidencial e que Furtado fosse retirado do cargo, algo que não aconteceu na sucessão entre Juscelino Kubitschek e Jânio Quadros. Após a renúncia deste último, quando o país passou por um curto período parlamentarista, o primeiro-ministro Tancredo Neves chegou a assinar a demissão de Furtado, que chegou a ser avisado pelo ministro Virgílio Távora de que havia unanimidade dos governadores do Nordeste para colocá-lo para fora. Nesse momento, houve uma curta passagem de Celso Furtado no recém criado Ministério do Planejamento.

Com o plebiscito favorável e a volta ao presidencialismo em 1963, Furtado teve seu cargo de superintendente da Sudene garantido pelo presidente João Goulart. Com a permanência de Furtado, aumentariam as tensões das reuniões do conselho deliberativo da Sudene: apenas contando com o apoio do governador Miguel Arraes os debates do conselho eram entrecortados pelas reivindicações de que alguns estados não recebiam recursos - mito desmontado por dados analisados pelo próprio Furtado — e se recebiam havia uma "predileção" por Pernambuco e Bahia em detrimento dos "pequenos". Ainda havia o argumento da parte de intelectuais conservadores, como Gilberto Freyre, que pedia maior participação do exército nas ações e criticava excessos economicistas e centralizadores das decisões da Sudene (COSTA LIMA, 2009: 231).

Para além dos conflitos com poderes locais, Furtado refletiu ainda " no calor dos acontecimentos" sobre a conjuntura política acirrada às vésperas do que seria o golpe civil-militar de 1964. Trata-se da obra A pré-revolução brasileira (1962). Nesse esforço de análise de conjuntura política, Celso Furtado analisa a sociedade brasileira com uma estrutura industrial já diversificada e defende as capacidades do Estado de encaminhar as reformas de base (como as do Plano Trienal). Furtado afirmava então sua 
forte crença em um projeto cepalino-keynesiano de reformas que pudessem acomodar disputas e tensões do capitalismo brasileiro dentro da democracia. Indicava também que este projeto não compactuava com o viés autoritário já sinalizado por setores militares e também destoava do caminho de modernização pela via "revolucionária" violenta que atraía, principalmente, setores estudantis rumo a uma visão de socialismo etapista, um “modelo soviético" (FURTADO, 1962). Como coloca Francisco de Oliveira (1981: 19), essas tensões previstas quase que de forma profética por Celso Furtado em 1962, cairiam no fim pelas "bordas" da direita autoritária com o aprofundamento do golpe de 1964 e o fechamento do regime em 1968. Com cassação de direitos e o exílio às portas, Furtado sofreria consequências do golpe e notaria a leitura errada vinda, talvez, de seu profundo senso de servidor técnico de Estado: não perceber uma relativa facilidade em que setores dominantes do capitalismo brasileiro acomodaram um projeto de (n)ação em um "recipiente" autoritário e militarizado.

\section{Considerações finais}

Ao pensar os pressupostos da nação interrompida, pensamos que a industrialização, para Celso Furtado seria um dos meios para que a perspectiva de uma nação que superasse seus fatores de atraso pudesse sonhar com o futuro. E o sonho, em Furtado, possui a dimensão da criatividade. Racionalizando os aspectos impeditivos para que a nação se integre, chega-se a uma perspectiva original da construção nacional: isto é, uma nação que não se constrói por projetos nacionais de desenvolvimento conflitantes, por visões de mundo encaixadas de forma bastante heterogêneas num contexto cultural, social, político e econômico, e que remete, todavia, ao mimetismo e ao modo como a resolução dos problemas nacionais esbarra na incapacidade recalcitrante para pensar soluções novas e nacionais por excelência.

Assim, o pensamento de Furtado dialoga com a tradição do pensamento social brasileiro ao chamar para si o esforço de "superação do atraso", pensado por diversos intelectuais dos séculos XIX e XX, mas somente em Furtado essa dimensão do tal "fator de atraso" ganha as conotações da integração geográfica e regional junto com a noção de fomento a uma unidade nacional que respeite o irredutível das identidades regionais; 
e nelas, o direito à criatividade, entendida esta em suas condições objetivas de acesso à educação, cultura e desenvolvimento. A atuação furtadiana à frente da SUDENE, contudo, recobra o contexto político, social e econômico em que as discussões sobre o desenvolvimento do nordeste se colocam; e abrem precedentes para pensar que a noção de integração regional em Furtado nasce com a noção de uma nação fragmentária em busca da construção histórica da unidade com outras regiões, ou seja, do próprio nordeste com o restante do Brasil.

Conflitos, visões de mundo atávicas e a pouca criatividade, entendida tanto no sentido macro como microssociológico, revelaram impeditivos e também potencialidades para a integração e industrialização do nordeste. Aqui, Furtado aproxima a noção de industrialização das condições objetivas através das quais as massas de trabalhadores da cidade e do campo poderiam ter acesso a uma das faces da modernidade. Ao longo deste artigo, buscamos demonstrar de que maneira esta nação interrompida, em Celso Furtado, passeou por momentos de potencialidade e impedimentos. Mas, sobretudo, como projetos de nação distintos se encontram subsumidos a uma formação nacional integrada e unificada, esforço de toda uma vida do centenário intelectual paraibano e sua obra.

\section{Referências bibliográficas}

ALBUQUERQUE JR, Durval Muniz de (2009). A invenção do Nordeste e outras artes. $4^{\mathrm{a}}$ ed. Recife: FJN; Ed. Massangana; São Paulo: Cortez.

BRESSER PEREIRA, L. C. (2015). A construção política do Brasil: sociedade, economia e Estado desde a independência. São Paulo, Editora 34.

CALlADO, A. (1960). Os industriais da seca e os galileus de Pernambuco. Rio de Janeiro: Editora Civilização Brasileira.

CAMPOS, J. B. (2014). Secas e políticas públicas no semiárido: ideias, pensadores e períodos. Estudos Avançados. [online]. vol.28, n.82, pp.65-88. Disponível em < http://www.scielo.br/scielo.php?script=sci_arttext\&pid=S010340142014000300005> Acesso em abril de 2020.

DANDARO, F; MARCONDES, R. (2018). Obras públicas no contexto regional: secas e gastos no Nordeste brasileiro (1860-1940). Revista Economia do Nordeste, Fortaleza, v. 49, jul/set: 113-127. Disponível em < https://ren.emnuvens.com.br/ren/article/download/777/730 $>$ Acesso em Abril de 2020

D'AGUIAR, R. (2009). A batalha da Sudene. In: FURTADO, C. O Nordeste e a saga da Sudene (1958- 1964). Arquivos Celso Furtado, vol. 3. $1^{\mathrm{a}}$ Ed. Rio de Janeiro: Contraponto/ Centro Internacional Celso Furtado de Políticas para o 
Desenvolvimento: 8-25.

FURTADO, R. (2009). O Nordeste e a saga da Sudene (1958-1964). Arquivos Celso Furtado, V.3 1 Ed - Rio de Janeiro: Contraponto/ Centro Internacional Celso Furtado de Política para o Desenvolvimento.

FERNANDES, Florestan (2005). A revolução burguesa no Brasil: ensaio de interpretação sociológica. 5a. Ed. São Paulo: Globo.

FURTADO, C. (1962). A pré-revolução brasileira. Rio de Janeiro: Fundo de Cultura. (1998). Seca e poder. Entrevista com Celso Furtado. São Paulo: Fundação Perseu Abramo.

(2009 [1959]). A Operação Nordeste: plano de ação. In: FURTADO, C. O Nordeste e a saga da Sudene (1958-1964). Arquivos Celso Furtado, vol. 3. $1^{\mathrm{a}} \mathrm{Ed}$. Rio de Janeiro: Contraponto/ Centro Internacional Celso Furtado de Políticas para o Desenvolvimento: 45.

(2013). A Operação Nordeste. In: AGUIAR, R. F (org.). Essencial Celso Furtado. Organização, apresentação e notas de Rosa Freide D'Aguiar. $1^{\text {a }}$ ed. São Paulo: Penguin Classics Companhia das Letras.

(2013b). O Nordeste: reflexões sobre uma política alternativa. In: AGUIAR, R. F (org.). Essencial Celso Furtado. Organização, apresentação e notas de Rosa Freide D’Aguiar. $1^{a}$ ed. São Paulo: Penguin Classics Companhia das Letras. (2013c). Nova concepção do federalismo. In: AGUIAR, R. F (org.). Essencial Celso Furtado. Organização, apresentação e notas de Rosa Freide D’Aguiar. $1^{\text {a }}$ ed. São Paulo: Penguin Classics Companhia das Letras.

(2013d). Acumulação e criatividade. In: AGUIAR, R. F (org.). Essencial Celso Furtado. Organização, apresentação e notas de Rosa Freide D'Aguiar. $1^{\text {a }}$ ed. São Paulo: Penguin Classics Companhia das Letras.

(2013e). Reflexões sobre a cultura brasileira. In: AGUIAR, R. F (org.). Essencial Celso Furtado. Organização, apresentação e notas de Rosa Freide D’Aguiar. $1^{\text {a }}$ ed. São Paulo: Penguin Classics Companhia das Letras.

GENNARO, E. G. (2019). Do fogo de monturo à chama das ligas camponesas: sociogênese de uma luta pela liberdade da terra na Paraíba. Dissertação de mestrado defendida no PPGCS-UFCG.

JULIÃO, F. (2009 [1962]). O que são as ligas camponesas? In WELCH, C. et al. Camponeses Brasileiros: leituras e interpretações clássicas (Volume 1). São Paulo, NEAD- UNESP: 271-198.

OLIVEIRA, F. (1981). Elegia para uma re(li)gião: Sudene, Nordeste, planejamento e con itos de classes. $2^{\mathrm{a}}$ Ed. Rio de Janeiro: Paz e Terra.

GARCIA JR, A. (2007). Os vice-reis do Norte: reconversão de elites agrárias e a Revolução de 1930 (1920-1964). Revista de Ciências Sociais, UFC, v. 38 (02): 74-87

COSTA LIMA, M. (2009). O conselho deliberativo da Sudene. In: FURTADO, C. A saga da Sudene (1958-1964). Arquivos Celso Furtado, vol. 3. $1^{\mathrm{a}}$ Ed. Rio de Janeiro: Contraponto/ Centro Internacional Celso Furtado de Política para o Desenvolvimento: 223-267.

VESENTINI, J. W. (2014). O conceito de região em três registros. Exemplificando o Nordeste Brasileiro. Confins revue franco-brésilienne de géographie, 34: 1-13, Disponível em < http://journals.openedition.org/confins/7377> Acesso em agosto de 2020.

VELLOSO, Mônica Pimenta (2010). História \& modernismo. Belo Horizonte: Autêntica Editora. 
BOTELHO, André (2002). Aprendizado do Brasil: a nação em busca dos seus portadores sociais. 1. Ed. Campinas: Editora Unicamp.

CANDIDO, Antônio (2006). A Sociologia no Brasil. Tempo Social: Revista de sociologia da USP, v. 18, n. 1. (2011a). Literatura de dois gumes. In: CANDIDO, Antônio. A educação pela noite \& outros ensaios. Rio de Janeiro: Ouro sobre Azul: 169-196.

(2011b). Literatura e subdesenvolvimento. In: A educação pela noite \& outros ensaios. Rio de Janeiro: Ouro sobre Azul: 197-217.

FLEET, Nicolas (2011). Did Weber have an adequate theory of nationalism? How did his theoretical understanding of nationalism relate to his own passionate German nationalism? Revista de Sociología. n. 26: 37-40.

GELLNER, Ernest (1996). O advento do nacionalismo e sua interpretação: os mitos da nação e da classe. In: BALAKRISHNAN, Golap (org.). Um mapa da questão nacional. Rio de Janeiro: Contraponto.

HOBSBAWM, Eric (1990). Nações e Nacionalismo desde 1780: programa, mito e realidade. Rio de Janeiro: Paz e Terra.

MICELI, Sérgio (2001). Intelectuais à brasileira. São Paulo, Companhia das Letras.

ORTIZ, Renato (2012). Cultura brasileira e identidade nacional. São Paulo: Brasiliense. (2013). Imagens do Brasil. Revista Sociedade e Estado, $\mathrm{n}^{\circ}$ 3, Brasília, UnB, v.8, Set/Dez.: 609-633.

RENAN, Ernest (1990). What is a nation? In: Homi Bhabha (org). Nation and Narration. London: Routledge.

RICUPERO, Bernardo (2011). Sete lições sobre as interpretações do Brasil. São Paulo: Alameda.

SCHWARCZ, Lilia Moritz (1993). O Espetáculo das Raças: Cientistas, Instituições E Questão Racial No Brasil. São Paulo: Companhia Das Letras.

SEVCENKO, Nicolau (1983). Literatura como missão: tensões sociais e criação cultural na Primeira República. 4. ed. São Paulo: Brasiliense.

SKIDMORE, Thomas (2012). Preto no branco: raça e nacionalidade no pensamento brasileiro (18701930). $1^{\text {a }}$. Ed. São Paulo: Companhia das Letras.

WEBER, M. (1974). A nação. In: __ _ Ensaios de sociologia. Rio de Janeiro: Zahar Editores.

Artigo recebido em 16 de agosto de 2020.

Aprovado em 06 de novembro de 2020.

DOI: 10.12957/intellectus.2020.53790 